\title{
Effect of bortezomib on proliferation and apoptosis of myeloma cells by activating Wnt/ $\beta$-catenin signaling pathway
}

\author{
YANLING DAI $^{1}$, XIAOMIN GUO ${ }^{2}$ and CHUNYAN YANG ${ }^{3}$ \\ ${ }^{1}$ Department of Medical Laboratory Technology, ${ }^{2}$ School of Nursing, ${ }^{3}$ Department of Pharmacy, \\ Chuxiong Medical College, Chuxiong, Yunnan 675000, P.R. China
}

Received November 4, 2019; Accepted November 14, 2019

DOI: $10.3892 / \mathrm{ol} .2020 .11678$

\begin{abstract}
Effect of bortezomib on proliferation and apoptosis of myeloma cells by activating Wnt/ $\beta$-catenin signaling pathway was investigated. Myeloma cells RPMI-8226 treated with different concentrations of bortezomib were used as experimental groups, and the untreated cells were used as the control group. The proliferation and apoptosis in all groups of cells were detected, as well as the expression levels of $\mathrm{Wnt} / \beta$-catenin signaling pathway-related proteins, $\beta$-catenin and c-Myc. The results revealed that bortezomib could inhibit the proliferation of myeloma cells. The apoptotic rates of RPMI-8226 cells in the groups treated with 20,50 and $80 \mathrm{nmol} / 1$ of bortezomib were $12.08 \pm 0.61,35.97 \pm 3.11$ and $57.22 \pm 5.47 \%$, respectively, which were significantly higher than that in the control group $(8.28 \pm 0.39 \%)(\mathrm{P}<0.05)$. The expression levels of $\beta$-catenin and c-Myc in the experimental groups were significantly lower than those in the control group $(\mathrm{P}<0.05)$. Bortezomib can reduce the expression level of $\mathrm{Wnt} / \beta$-catenin signaling pathway-related proteins, $\beta$-catenin and c-Myc, and may inhibit cell proliferation and accelerate apoptosis by activating the $\mathrm{Wnt} / \beta$-catenin signaling pathway.
\end{abstract}

\section{Introduction}

Myeloma is also called plasmacytoma. Multiple myeloma (MM), a malignant monoclonal plasma cell disease (1), is most common in clinic and usually occurs in middle-aged and elderly individuals. MM accounts for $\sim 10 \%$ of blood tumors and $1 \%$ of systemic malignant tumors (2), and its incidence increases with age (3). Chemotherapy and autologous hematopoietic stem cell transplantation (4) are currently the two most commonly used treatment methods for MM patients.

Correspondence to: Dr Chunyan Yang, Department of Pharmacy, Chuxiong Medical College, 82 Xinshi Street, Chuxiong, Yunnan 675000, P.R. China

E-mail: yes74o@163.com

Key words: bortezomib, signaling pathway, myeloma, cell proliferation, cell apoptosis
As the pathogenesis of MM is not clear yet (5), although the survival rate of $\mathrm{MM}$ patients has improved, the recurrence rate is still very high (6). Wnt/ $\beta$-catenin signaling pathway has the effects of regulating gene expression, cell invasion, migration, proliferation and differentiation, and is involved in the occurrence and development of bone cancer (7). A previous study by Savvidou et al (8) has shown that $\mathrm{Wnt} / \beta$-catenin signaling pathway is abnormally regulated in the advanced stage of MM disease. However, bortezomib is a proteasome inhibitor (9). Qiang et al (10) have shown that bortezomib can induce activation of $\mathrm{Wnt} / \beta$-catenin pathway and differentiation of mesenchymal stem cells into osteoblasts. At present, research has proven that bortezomib has good therapeutic effect on MM; however, the exact therapeutic mechanism of bortezomib has not been fully understood. In the present study, the effect of bortezomib on the proliferation and apoptosis of myeloma cells by activating the $\mathrm{Wnt} / \beta$-catenin signaling pathway was investigated, aiming to uncover the mechanism of bortezomib in the treatment of MM and provide reference and guidance for the clinical treatment of such diseases.

\section{Materials and methods}

Reagents and materials. Human MM cell line RPMI-8226 was provided by the BeNa Culture Collection (BNCC338295). The following kits were used: CCK-8 kit (IC-CCK-Hu; Shanghai Yu Bo Biotech Co., Ltd.), TRIzol ${ }^{\circledR}$ kit (5301100; Shanghai Mingjin Biology Co., Ltd.), RNasin Inhibitor (R8060; Beijing Solarbio Science \& Technology Co.), RT kit (CD-102539GM) and Dual-Luciferase Reporter Assay kit (CDLG-4997) (both from ChunduBio), RIPA (JN0190-HBJ; Beijing Biolab Science and Technology Co, Ltd.), BCA Protein Assay kit (QC12533-A; Shanghai Qincheng Biotechnology Co., Ltd.), ECL kit (H-E-60/H-E-125/H-E-250; Shanghai Chuan Qiu Biotechnology Co., Ltd.), Annexin V/PI Apoptosis Detection kit (AD10-2; Shanghai Jingke Chemical Technology Co., Ltd.), RNA Amplification kit (HZ-051021; Zhen Shanghai and Shanghai Industrial Co., Ltd.), SYBR Green I (KS26757; Shanghai Keshun Biological Technology Co., Ltd.), $\beta$-catenin and c-Myc antibodies (YT656 and K12862, respectively; both from Beijing Biolab Science and Technology Co.,Ltd.), GAPDH antibody (10900R; Shanghai Caiyou Industrial Co., Ltd.), HRP-labeled secondary antibody (YDJ3235; Shanghai Yuduo Biological Technology Co., Ltd.), microplate reader (BioTek 
Table I. Primer sequences.

\begin{tabular}{lc}
\hline Genes & \multicolumn{1}{c}{ Primer sequences } \\
\hline $\begin{array}{l}\text { 3-catenin } \\
\text { Upstream }\end{array}$ & 5'-CGCATGGAGGAGATAGTTG-3' \\
Downstream & 5'-CGAAAGCCGTTTCTTGTAG-3' \\
c-Myc & \\
Upstream & 5'-CCTACCCTCTCAACGACAGC-3' \\
Downstream & 5'-GTTGTGTGTTCGCCTCTTGA-3' \\
GAPDH & \\
Upstream & 5'-ACAGCAACAGGGTGGTGGAC-3' \\
Downstream & 5'-TTTGAGGGTGCAGCGAACTT-3' \\
\hline
\end{tabular}

Instruments, Inc.), flow cytometer (FACSCanto II; Becton, Dickinson and Company), GAPDH (Cell Signaling Technology, Inc.). All primers were designed and synthesized by the Shanghai GenePharma Co., Ltd.

The study was approved by the Ethics Committee of Chuxiong Medical College (Chuxiong, China).

Cell line culture, grouping and administration. RPMI-8226 human myeloma cells were transferred to a medium containing $10 \%$ fetal bovine serum and were cultured in a constant temperature incubator at $37^{\circ} \mathrm{C}$ with $5 \% \mathrm{CO}_{2}$ for $24 \mathrm{~h}$. Next, 20 , 50 and $80 \mathrm{nmol} / 1$ of bortezomib were added, respectively. No drugs were added to the control group. The cells of each group were collected after $24 \mathrm{~h}$ of treatment.

CCK-8 detection of cell proliferation. After treatment, the cells of the experimental and control groups were collected, inoculated on 96-well plates, and then cultured for 24, 48, 72 and $96 \mathrm{~h}$. The cells were cultured in a $5 \% \mathrm{CO}_{2}$ incubator at $37^{\circ} \mathrm{C}, 10 \mu \mathrm{l}$ of CCK- 8 solution was added to each well, and the culture was continued for 1-4 h. The OD value of each group of cells was measured under $450 \mathrm{~nm}$ absorbance by using an enzyme-labeled instrument.

Detection of apoptosis by flow cytometry. The treated cells were digested with pancreatin, washed with PBS, added with $100 \mu \mathrm{l}$ of binding buffer, and then prepared into $1 \times 10^{6} / \mathrm{ml}$ suspension. Annexin V-FITC and PI were added, and the cells were incubated at room temperature in the dark for $20 \mathrm{~min}$. The apoptotic rate of the cells was analyzed using a flow cytometer and FACSCanto II software.

Detection of $\beta$-catenin and $c$-Myc gene expression by reverse transcription-quantitative PCR (RT-qPCR). Total RNA was extracted from the RPMI-8226 cells of each group using TRIzol ${ }^{\circledR}$ reagent. Total RNA was reverse transcribed into cDNA. Reaction system: $1 \mu \mathrm{l}$ M-MLV, $1 \mu \mathrm{l}$ Oligo(dT), $0.5 \mu \mathrm{l}$ RNasin Inhibitor, $1 \mu \mathrm{l} \mathrm{dNTPs}$, and RNAse-free water was added to a final volume of $15 \mu \mathrm{l}$. Following incubation at $38^{\circ} \mathrm{C}$ for $60 \mathrm{~min}, 1 \mu \mathrm{l}$ of cDNA was collected at $85^{\circ} \mathrm{C}$ for $5 \mathrm{sec}$. The synthesized cDNA was used as template for the RT-qPCR amplification. GAPDH was used as internal reference for $\beta$-catenin and $\mathrm{c}-\mathrm{Myc}$, and the reaction conditions
RPMI-8226

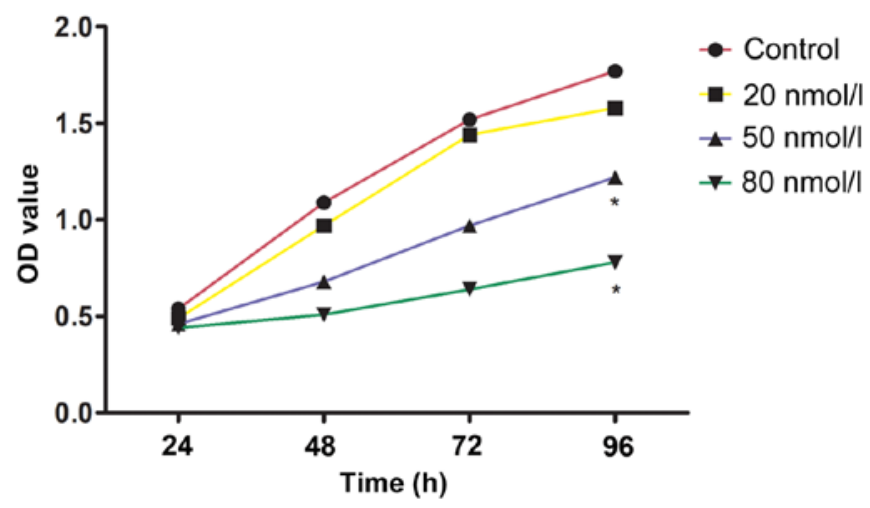

Figure 1. Comparison of proliferation ability among groups. After $96 \mathrm{~h}$, the proliferation ability of the RPMI- 8226 cells treated with 20,50 and $80 \mathrm{nmol} / 1$ bortezomib was lower compared with that of the control group. The proliferation abilities of the cells in the control group and those treated with $20 \mathrm{nmol} / 1$ bortezomib had no statistically significant difference $(\mathrm{P}>0.05)$; however, the proliferation ability was significantly higher than that of the cells treated with 50 and $80 \mathrm{nmol} / 1$ bortezomib $(\mathrm{P}<0.05)$. ${ }^{*} \mathrm{P}<0.05$, compared with the cells treated with $20 \mathrm{nmol} / 1$ bortezomib.

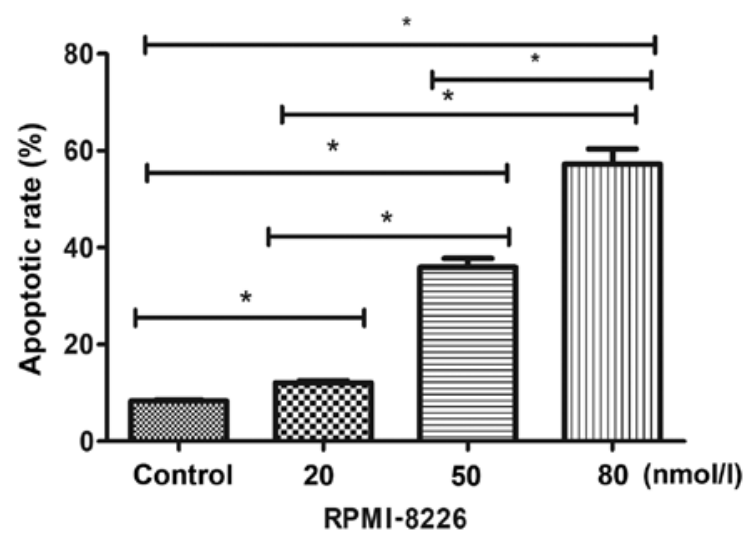

Figure 2. Comparison of apoptotic rate among groups. The apoptotic rate in the control group was significantly lower than that of the cells treated with 20, 50 and $80 \mathrm{nmol} / 1$ bortezomib. ${ }^{*} \mathrm{P}<0.05$.

were: Pre-denaturation at $95^{\circ} \mathrm{C}$ for $30 \mathrm{sec}$, denaturation at $95^{\circ} \mathrm{C}$ for $5 \mathrm{sec}, 60^{\circ} \mathrm{C}$ for $20 \mathrm{sec}$, for 40 cycles. Each experiment was repeated 3 times and the relative expression of the genes was detected by $2^{-\Delta \mathrm{Cq}}$ method (11). Primer sequences are shown in Table I.

Detection of $\beta$-catenin and $c$-Myc protein expression by western blot analysis. RIPA was used to lyse the cells and extract total protein. Protein concentration was quantified by BCA. Samples of $0,1,2,3$ and $4 \mu \mathrm{l}$ were added to the wells, respectively, and the concentration was adjusted to $20 \mu \mathrm{g} / \mu \mathrm{l}$. A total of $40 \mu \mathrm{g}$ protein/lane were separated via $12 \%$ SDS-PAGE and transferred onto a PVDF membrane. The corresponding bands were selected according to the target protein. The separated proteins were blocked with $5 \%$ of skim milk powder at room temperature for $1.5 \mathrm{~h}$. TBST was used to wash the membranes for $3 \mathrm{~min}$. After washing, $2 \mathrm{ml}$ of western primary antibody solution consisting of $\beta$-catenin $(1: 1,000)$, c-Myc $(1: 500)$ and GAPDH $(1: 1,000)$ was added and the membranes 
A

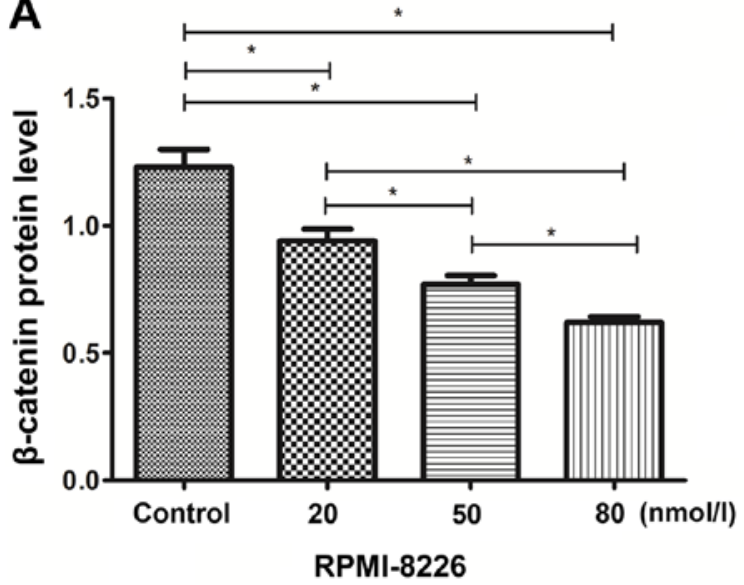

B

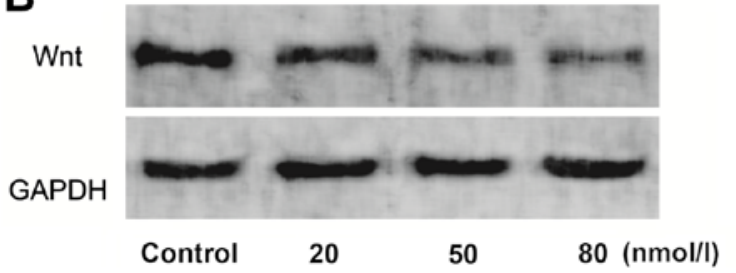

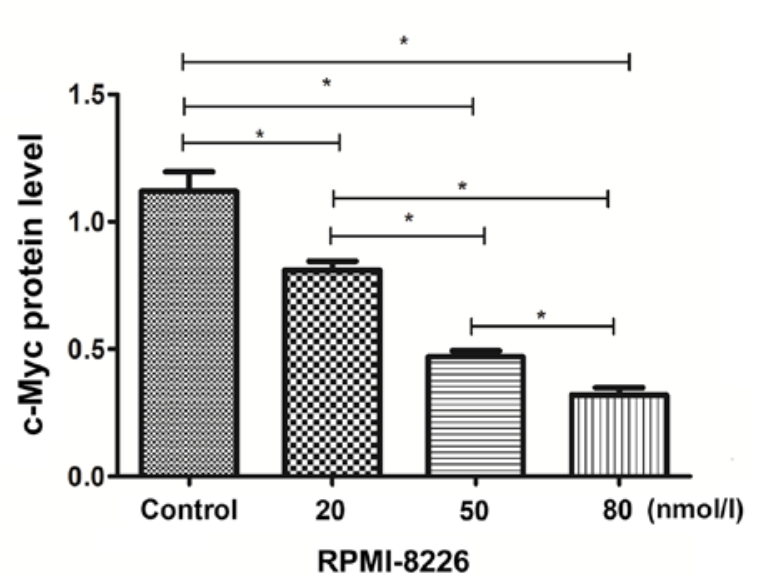

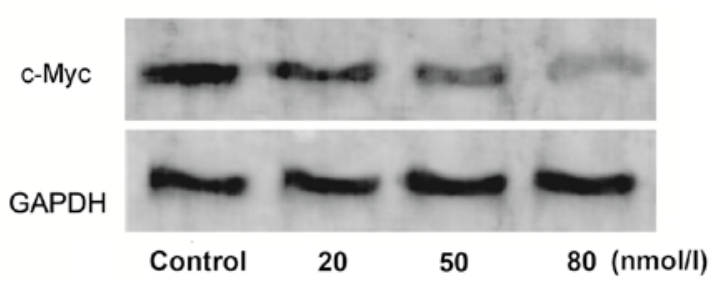

Figure 3. Detection of the protein expression of $\beta$-catenin and c-Myc in each group of cells using western blot analysis. (A) The protein expression levels of $\beta$-catenin and c-Myc proteins in the experimental groups were lower than those in the control group. *P<0.05. (B) Western blots.

were stored at $4^{\circ} \mathrm{C}$ overnight. On the next day, the membranes were incubated with primary antibodies for $30 \mathrm{~min}$. Following the primary incubation, the membranes were incubated with HRP-labeled secondary antibody $(1: 1,000)$ for $1 \mathrm{~h}$ at $37^{\circ} \mathrm{C}$ and were rinsed 3 times with PBS for 5 min each time. Protein bands were visualized in a dark room. ECL was carried out and the protein expression levels were determined. GAPDH was used as an internal reference for the analysis of the relative expression of each indicator. The results were analyzed by Image $\mathrm{Lab}^{\mathrm{TM}}$ software (Bio-Rad Laboratories, Inc.).

Observational indexes. The proliferation and apoptosis of cells in the experimental and control groups were observed. The expression levels of $\beta$-catenin and c-Myc in each group of cells were also observed.

Statistical analysis. SPSS 22.0 software (IBM Corp.) was used for data analysis. Measurement data were expressed as the mean \pm SD. The comparison of measurement data between two groups was made by independent samples t-test, and among multiple groups by one-way ANOVA (expressed as F-value). LSD post hoc test was used for pairwise comparisons. Repeated measures ANOVA was used for multi time-point expression (expressed as F-value) and the Bonferroni test was used as the post hoc test. $\mathrm{P}<0.05$ was considered to indicate a statistically significant difference.

\section{Results}

Comparison of proliferation ability among groups. The results of CCK-8 detection revealed that, compared with the control group, the proliferation ability of the cells treated with 20, 50 and $80 \mathrm{nmol} / \mathrm{l}$ of bortezomib was reduced. There was no significant difference between the proliferation ability of the cells treated with $20 \mathrm{nmol} / \mathrm{l}$ of bortezomib and that of the cells in the control group, and both were higher than the proliferation ability of the cells treated with 50 and $80 \mathrm{nmol} / 1$ of bortezomib $(\mathrm{P}<0.05)$ (Fig. 1).

Comparison of apoptotic rate among groups. Flow cytometry analysis of cell apoptosis revealed that the apoptotic rates of RPMI-8226 cells treated with 20,50 and $80 \mathrm{nmol} / 1$ of bortezomib were $12.08 \pm 0.61,35.97 \pm 3.11$ and $57.22 \pm 5.47 \%$, respectively, which were significantly higher than the apoptotic rate of the cells in the control group $(8.28 \pm 0.39 \%),(\mathrm{P}<0.05)$, in a dose-dependent manner (Fig. 2).

Effect of bortezomib on Wnt/ $\beta$-catenin signaling pathway. The expression of the $\mathrm{Wnt} / \beta$-catenin signaling pathway-related proteins, $\beta$-catenin and c-Myc, was detected by western blot analysis. The protein expression levels of $\beta$-catenin and c-Myc in the RPMI-8226 cells of the control group were significantly higher than those in the bortezomib-treated groups (Fig. 3).

The expression of $\beta$-catenin and c-Myc in each group of cells was detected by RT-qPCR. The results showed that the expression levels of $\beta$-catenin and c-Myc in the RPMI-8226 cells of the control group were significantly higher than those in the bortezomib-treated groups (Fig. 4).

\section{Discussion}

MM can lead to osteolytic lesions and fractures in the body (12), and almost all MM cases present painless, pre-malignant lesions, known as uncertain monoclonal hematopathy (13). The annual incidence rate of MM ranks second among all hematological malignancies (14), and MM is especially prevalent 

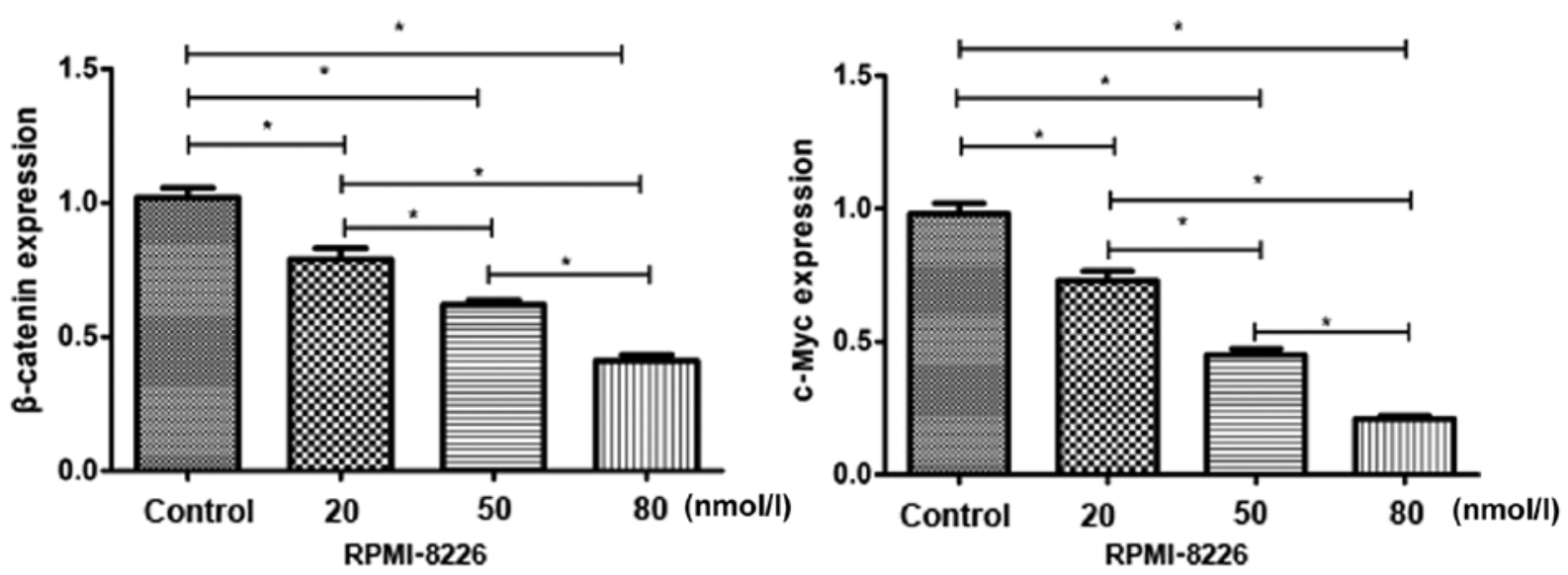

Figure 4. RT-qPCR detection of $\beta$-catenin and c-Myc expression in each group of cells. The expression levels of $\beta$-catenin and c-Myc in the experimental groups were lower than those in the control group, and the higher the dose was, the lower the expression. ${ }^{*} \mathrm{P}<0.05$.

in middle-aged and elderly individuals. Although in recent years a number of studies have been reported on MM and the understanding of myeloma diseases is getting deeper, MM is still an incurable disease due to its unclear pathogenesis, drug resistance and disease recurrence.

At present, the main treatments for MM are chemotherapy, immunotherapy,and autologous stem celltransplantation(15-17). Autologous stem cell transplantation has a huge toxic effect, thus requiring long-term hospitalization. Immunomodulatory drugs and proteasome inhibitors can significantly improve the prognosis of patients (18). Proteome is an enzyme that exists in all cells and plays an important role in cell growth and function. Bortezomib, as a proteasome inhibitor, can cause cancer cells to die or not grow any further (19). However, due to its drug resistance, bortezomib is not the best treatment method for MM. Bortezomib drug resistance is an urgent clinical problem to be solved. It is very important to find a treatment method to overcome bortezomib drug resistance (20). A number of studies have confirmed that the activation of Wnt/ $\beta$-catenin signaling pathway is positively correlated with the prognosis of various malignant tumors $(21,22)$. Transcription mediated by the $\beta$-catenin/Tcf promotes cell proliferation, survival and invasion (23). $\beta$-catenin is a downstream effector of Wnt signaling pathway that regulates cell proliferation and differentiation (24). Typical Wnt/ $\beta$-catenin signaling pathway has been extensively studied as a target for tumor therapy (25). The present study aimed to investigate the effect of bortezomib on proliferation and apoptosis of myeloma cells by activating Wnt/ $/$-catenin signaling pathway, in order to provide a reference for the study of drug resistance.

In the present study, the proliferation abilities of bortezomib-treated and untreated myeloma RPMI-8226 cells were compared, and the results showed that the proliferation ability of myeloma cells treated with 20,50 and $80 \mathrm{nmol} / 1$ of bortezomib was lower than that of the control group after $96 \mathrm{~h}$. In addition, the proliferation ability of myeloma cells treated with 50 and $80 \mathrm{nmol} / 1$ of bortezomib was significantly lower than that of the control group $(\mathrm{P}<0.05)$. Furthermore, the apoptotic rate of each group of cells was analyzed by Annexin V-FITC/PI flow cytometry. The apoptotic rate of the cells treated with bortezomib was significantly higher than that of the untreated control group $(\mathrm{P}<0.05)$, which also showed that bortezomib has the effect of promoting myeloma cell apoptosis. These results are consistent with previous studies $(26,27)$. Finally, the expression levels of $\mathrm{Wnt} / \beta$-catenin signaling pathway-related proteins $\beta$-catenin and $\mathrm{c}-\mathrm{Myc}$ were detected in each group by two methods. The expression levels of $\beta$-catenin and c-Myc in myeloma cells treated with bortezomib were lower than those in the control group, and were decreased in a dose-dependent manner. Jin et al (28) have shown that the sensitivity of myeloma cells to bortezomib can be enhanced by regulating Wnt/ $\beta$-catenin signaling pathway. At present, numerous studies have confirmed that Wnt/ $\beta$-catenin signaling pathway is related to hematological tumors (29-31), such as lymphoma, in accordance to the results of this study and supporting our conclusions.

There are some deficiencies in the presented study. First of all, normal cells were not included in this research and the effect of bortezomib on normal cells was not investigated. Secondly, due to the small number of research samples, individual differences are not excluded. Finally, the effect of bortezomib on the regulation of related proteins was not studied and further research is required to improve our results.

In conclusion, bortezomib may reduce myeloma cell proliferation and accelerate cell apoptosis by activating the $\mathrm{Wnt} / \beta$-catenin signaling pathway.

\section{Acknowledgements}

Not applicable.

\section{Funding}

No funding was received.

\section{Availability of data and materials}

The datasets used and/or analyzed during the current study are available from the corresponding author on reasonable request.

\section{Authors' contributions}

YD analyzed and interpreted the data, and wrote the manuscript. XG designed the study and performed the experiments. 
CY was responsible for the analysis and discussion of the data. All authors read and approved the final manuscript.

\section{Ethics approval and consent to participate}

The study was approved by the Ethics Committee of Chuxiong Medical College (Chuxiong, China).

\section{Patient consent for publication}

Not applicable.

\section{Competing interests}

The authors declare that they have no competing interests.

\section{References}

1. Bolli N, Avet-Loiseau H, Wedge DC, Van Loo P, Alexandrov LB, Martincorena I, Dawson KJ, Iorio F, Nik-Zainal S, Bignell GR, et al: Heterogeneity of genomic evolution and mutational profiles in multiple myeloma. Nat Commun 5: 2997, 2014.

2. Moreau P, San Miguel J, Sonneveld P, Mateos MV, Zamagni E, Avet-Loiseau H, Hajek R, Dimopoulos MA, Ludwig H, Einsele H, et al; ESMO Guidelines Committee: Multiple myeloma: ESMO Clinical Practice Guidelines for diagnosis, treatment and follow-up. Ann Oncol 28 (Suppl 4): iv52-iv61, 2017.

3. Mateos MV, Dimopoulos MA, Cavo M, Suzuki K, Jakubowiak A, Knop S, Doyen C, Lucio P, Nagy Z, Kaplan P, et al; ALCYONE Trial Investigators: Daratumumab plus bortezomib, melphalan, and prednisone for untreated myeloma. N Engl J Med 378 : $518-528,2018$

4. Rodriguez TE, Hari P, Stiff PJ, Smith SE, Sterrenberg D and Vesole DH: Busulfan, melphalan, and bortezomib versus high-dose melphalan as a conditioning regimen for autologous hematopoietic stem cell transplantation in multiple myeloma. Biol Blood Marrow Transplant 22: 1391-1396, 2016.

5. Ocio EM, Richardson PG, Rajkumar SV, Palumbo A, Mateos MV, Orlowski R, Kumar S, Usmani S, Roodman D, Niesvizky R, et al: New drugs and novel mechanisms of action in multiple myeloma in 2013: A report from the International Myeloma Working Group (IMWG). Leukemia 28: 525-542, 2014.

6. Stewart AK, Rajkumar SV, Dimopoulos MA, Masszi T, Špička I, Oriol A, Hájek R, Rosiñol L, Siegel DS, Mihaylov GG, et al, ASPIRE Investigators: Carfilzomib, lenalidomide, and dexamethasone for relapsed multiple myeloma. N Engl J Med 372 $142-152,2015$

7. Tian J, He H and Lei G: Wnt/ $\beta$-catenin pathway in bone cancers. Tumour Biol 35: 9439-9445, 2014.

8. Savvidou I, Khong T, Cuddihy A, McLean C, Horrigan S and Spencer A: $\beta$-catenin inhibitor BC2059 is efficacious as monotherapy or in combination with proteasome inhibitor bortezomib in multiple myeloma. Mol Cancer Ther 16: 1765-1778, 2017.

9. Palumbo A, Chanan-Khan A, Weisel K, Nooka AK, Masszi T, Beksac M, Spicka I, Hungria V, Munder M, Mateos MV, et al; CASTOR Investigators: Daratumumab, bortezomib, and dexamethasone for multiple myeloma. N Engl J Med 375: 754-766, 2016.

10. Qiang YW, Heuck CJ, Shaughnessy JD Jr, Barlogie and Epstein J: Proteasome inhibitors and bone disease. Semin Hematol 49: 243-248, 2012.

11. Vergara-Ortega DN, Sevilla-Reyes EE, Herrera-Ortiz A, Torres-Ibarra L, Salmerón J, Lazcano-Ponce E and SánchezAlemán MA: Real time PCR to evaluate HSV-2 shedding from anal and genital samples among men who have sex with men, living with HIV. J Med Virol 90: 745-752, 2018.

12. Fairfield H, Falank C, Avery L and Reagan MR: Multiple myeloma in the marrow: Pathogenesis and treatments. Ann N Y Acad Sci 1364: 32-51, 2016.

13. Dimopoulos K, Gimsing P and Grønbæk K: The role of epigenetics in the biology of multiple myeloma. Blood Cancer $\mathrm{J} 4$ e207, 2014.
14. Saki N,Abroun S,HajizamaniS,RahimFand Shahjahani M: Association of chromosomal translocation and miRNA expression with the pathogenesis of multiple myeloma. Cell J 16: 99-110, 2014.

15. Nijhof IS, Groen RWJ, Noort WA, van Kessel B, de Jong-Korlaar R, Bakker J, van Bueren JJ, Parren PW, Lokhorst HM, van de Donk NW, et al: Preclinical evidence for the therapeutic potential of CD38-targeted immuno-chemotherapy in multiple myeloma patients refractory to lenalidomide and bortezomib. Clin Cancer Res 21: 2802-2810, 2015.

16. Grövdal M, Nahi H, Gahrton G, Liwing J, Waage A, Abildgaard N, Pedersen PT, Hammerstrøm J, Laaksonen A, Bazia P, et al: Autologous stem cell transplantation versus novel drugs or conventional chemotherapy for patients with relapsed multiple myeloma after previous ASCT. Bone Marrow Transplant 50: 808-812, 2015

17. Zhao X, Ji CY, Liu GQ, Ma DX, Ding HF, Xu M and Xing J: Immunomodulatory effect of DC/CIK combined with chemotherapy in multiple myeloma and the clinical efficacy. Int J Clin Exp Pathol 8: 13146-13155, 2015.

18. Palumbo A, Cavallo F, Gay F, Di Raimondo F, Ben Yehuda D, Petrucci MT, Pezzatti S, Caravita T, Cerrato C, Ribakovsky E, et al: Autologous transplantation and maintenance therapy in multiple myeloma. N Engl J Med 371: 895-905, 2014.

19. Scott K, Hayden PJ, Will A, Wheatley K and Coyne I: Bortezomib for the treatment of multiple myeloma. Cochrane Database Syst Rev 4: CD010816, 2016.

20. Tabayashi T, Takahashi Y, Kimura Y, Tomikawa T, Sagawa M, Nemoto T, Watanabe R, Tokuhira M, Mori S and Kizaki M: Targeting the Wnt/ $\beta$-catenin signaling pathway in multiple myeloma: A possible new therapeutic approach to overcome bortezomib-resistance. Blood 124: 3372, 2014.

21. Jang GB, Kim JY, Cho SD, Park KS, Jung JY, Lee HY, Hong IS and Nam JS: Blockade of Wnt/ $\beta$-catenin signaling suppresses breast cancer metastasis by inhibiting CSC-like phenotype. Sci Rep 5: 12465, 2015.

22. Kim JY, Lee HY, Park KK, Choi YK, Nam JS and Hong IS: CWP232228 targets liver cancer stem cells through Wnt/ $\beta$-catenin signaling: a novel therapeutic approach for liver cancer treatment. Oncotarget 7: 20395-20409, 2016.

23. Xu Y, Yang Z, Yuan H, Li Z, Li Y, Liu Q and Chen J: PCDH10 inhibits cell proliferation of multiple myeloma via the negative regulation of the $\mathrm{Wnt} / \beta$-catenin/BCL-9 signaling pathway. Oncol Rep 34: 747-754, 2015.

24. Su N, Wang P and Li Y: Role of $\mathrm{Wnt} / \beta$-catenin pathway in inducing autophagy and apoptosis in multiple myeloma cells. Oncol Lett 12: 4623-4629, 2016.

25. Ashihara E, Takada T and Maekawa T: Targeting the canonical Wnt $/ \beta$-catenin pathway in hematological malignancies. Cancer Sci 106: 665-671,2015.

26. Pati ML, Vitale P, Ferorelli S, Iaselli M, Miciaccia M, Boccarelli A, Di Mauro GD, Fortuna CG, Souza Domingos TF, Rodrigues Pereira da Silva LC, et al: Translational impact of novel widely pharmacological characterized mofezolac-derived COX-1 inhibitors combined with bortezomib on human multiple myeloma cell lines viability. Eur J Med Chem 164: 59-76, 2019.

27. Yin L, Kufe T, Avigan D and Kufe D: Targeting MUC1-C is synergistic with bortezomib in downregulating TIGAR and inducing ROS-mediated myeloma cell death. Blood 123: 2997-3006, 2014.

28. Jin Y, Xu L, Wu X, Feng J, Shu M, Gu H, Gao G, Zhang J, Dong B and Chen X: Synergistic efficacy of the demethylation agent decitabine in combination with the protease inhibitor bortezomib for treating multiple myeloma through the Wnt/ $\beta$-catenin pathway. Oncol Res 27: 729-737, 2019.

29. Zhang P, Zhao X, Zhang W, He A, Lei B, Zhang W and Chen Y: Leukemia-associated gene MLAA-34 reduces arsenic trioxide-induced apoptosis in HeLa cells via activation of the Wnt/ $\beta$-catenin signaling pathway. PLoS One 12: e0186868, 2017.

30. Chung J, Karkhanis V, Baiocchi RA and Sif S: Protein arginine methyltransferase 5 (PRMT5) promotes survival of lymphoma cells via activation of $\mathrm{WNT} / \beta$-catenin and AKT/GSK3 $\beta$ proliferative signaling. J Biol Chem 294: 7692-7710, 2019.

31. Walker MP, Stopford CM, Cederlund M, Fang F, Jahn C, Rabinowitz AD, Goldfarb D, Graham DM, Yan F, Deal AM, et al: FOXP1 potentiates $\mathrm{Wnt} / \beta$-catenin signaling in diffuse large B cell lymphoma. Sci Signal 8: ra12-ra12, 2015.

This work is licensed under a Creative Commons Attribution-NonCommercial-NoDerivatives 4.0 International (CC BY-NC-ND 4.0) License. 